\title{
REVIEW
}

Open Access

\section{Alcohol use disorders and the risk of progression of liver disease in people with hepatitis $C$ virus infection - a systematic review}

Laura Llamosas-Falcón ${ }^{1,2}$, Kevin D. Shield ${ }^{2,3}$, Maya Gelovany' ${ }^{2}$ Jakob Manthey ${ }^{4,5}$ and Jürgen Rehm ${ }^{2,3,5,6,7,8,9^{*}}$ (D)

\begin{abstract}
Liver cirrhosis and other chronic liver diseases are usually compartmentalized into separate categories based on etiology (e.g., due to alcohol, virus infection, etc.), but it is important to study the intersection of, and possible interactions between, risk factors. The aim of this study is to summarize evidence on the association between alcohol use disorders (AUDs) and decompensated liver cirrhosis and other complications in patients with chronic Hepatitis C virus ( $\mathrm{HCV}$ ) infection. A systematic search of epidemiological studies was conducted using Ovid Medline databases in accordance with the Preferred Reporting Items for Systematic Reviews and Meta-Analyses criteria. Relative Risk estimates were combined using random-effects meta-analyses. The proportion of cases with liver disease progression that could be avoided if no person with a chronic HCV infection had an AUD was estimated using an attributable fraction methodology. A total of 11 studies fulfilled the inclusion criteria, providing data from 286,641 people with chronic HCV infections, of whom 63,931 (22.3\%) qualified as having an AUD. Using decompensated liver cirrhosis as the outcome for the main meta-analysis ( $n=7$ unique studies), an AUD diagnosis was associated with a 3.3-fold risk for progression of liver disease among people with a chronic HCV infection (95\% Confidence Interval (Cl): 1.8-4.8). In terms of population-attributable fractions, slightly less than 4 out of 10 decompensated liver cirrhosis cases were attributable to an AUD: 35.2\% (95\% Cl: 16.2-47.1\%). For a secondary analyses, all outcomes related to liver disease progression were pooled (i.e., liver deaths or cirrhosis in addition to decompensated liver cirrhosis), which yielded a similar overall effect ( $n=13$ estimates; $\mathrm{OR}=3.7 ; 95 \% \mathrm{Cl}: 2.2-5.3)$ and a similar attributable fraction (39.3\%; 95\% Cl: 21.9-50.4\%). In conclusion, AUDs were frequent in people with chronic HCV infections and contributed to worsening the course of liver disease. Alcohol use and AUDs should be assessed in patients who have liver disease of any etiology, and interventions should be implemented to achieve abstinence or to reduce consumption to the greatest possible extent.
\end{abstract}

Keywords: Alcohol, Alcohol-use-disorders, Hepatitis C virus infection, Liver-disease progression, Liver cirrhosis, Decompensated liver cirrhosis, Meta-analysis

\footnotetext{
* Correspondence: jtrehm@gmail.com

${ }^{2}$ Institute for Mental Health Policy Research, Centre for Addiction and Mental Health, 33 Russell Street, Room T420, Toronto, Ontario M5S 2S1, Canada

${ }^{3}$ Dalla Lana School of Public Health, University of Toronto, 155 College Street, Toronto, Ontario M5T 1 P8, Canada

Full list of author information is available at the end of the article
}

\section{$\triangle B M C$}

(c) The Author(s). 2020 Open Access This article is licensed under a Creative Commons Attribution 4.0 International License, which permits use, sharing, adaptation, distribution and reproduction in any medium or format, as long as you give appropriate credit to the original author(s) and the source, provide a link to the Creative Commons licence, and indicate if changes were made. The images or other third party material in this article are included in the article's Creative Commons licence, unless indicated otherwise in a credit line to the material. If material is not included in the article's Creative Commons licence and your intended use is not permitted by statutory regulation or exceeds the permitted use, you will need to obtain permission directly from the copyright holder. To view a copy of this licence, visit http://creativecommons.org/licenses/by/4.0/ The Creative Commons Public Domain Dedication waiver (http://creativecommons.org/publicdomain/zero/1.0/) applies to the data made available in this article, unless otherwise stated in a credit line to the data. 


\section{Main text}

\section{The compartmentalization of liver cirrhosis}

Both epidemiologically and clinically, liver cirrhosis and other chronic liver diseases are generally compartmentalized into separate categories based on their etiology. Thus, the Global Health Estimates [1] or the Global Burden of Disease Study [2] give prevalence, incidence, and mortality rates for them in different categories, separating cirrhosis and other chronic liver diseases by etiology: alcohol use, hepatitis B virus infection, hepatitis $\mathrm{C}$ virus $(\mathrm{HCV})$ infection, non-alcoholic steatohepatitis, and other causes. Similar differentiation can be found clinically and in the International Classification of Diseases [3], even though there have been some calls to change this system [4, 5]. This contribution will not focus on the logic of current classifications, but will look at the intersection between two of these seemingly separate categories, i.e. liver diseases due to alcohol use and due to $\mathrm{HCV}$ infection.

\section{Aims of the current contribution}

Based on a systematic literature search, we examined the role of heavy alcohol use-as operationalized via alcohol use disorders (AUDs) [6, 7]-on the progression of liver disease in people with chronic HCV infection. We hypothesized, based on a recent large-scale retrospective cohort study on all hospitalizations in France [8], that a large proportion of complications arising over the course of liver disease in people with HCV infection is attributable to AUD. The main outcome was "decompensated liver cirrhosis", defined as an acute deterioration in liver function in a patient with cirrhosis, and characterized by jaundice, ascites, hepatic encephalopathy, hepatorenal syndrome and/or variceal hemorrhage [9, 10]. We will summarize the link between AUDs and decompensated liver cirrhosis and other complications of liver disease in people with $\mathrm{HCV}$ infection, by pooling relevant studies using meta-analytical techniques [11].

\section{Methods}

\section{Systematic search and inclusion/exclusion}

As a first step, we conducted a systematic search of epidemiological studies on the relationship between alcohol use and progression of liver disease due to $\mathrm{HCV}$, using Ovid Medline databases, and applying the Preferred Reporting Items for Systematic Reviews and MetaAnalyses (PRISMA) criteria [12]. The exact search terms can be found in the Supplementary Materials (Table S1), but we looked for cohort or case-control studies (for definition, see [13]) of people with chronic HCV infections; with at least two different forms of alcohol use (e.g., alcohol use yes/no; AUD yes/no); and a verified indicator of progression of liver disease (e.g., progression of fibrosis, progression of cirrhosis to decompensated cirrhosis; liver death). This search was initially conducted on July 28, 2019 and updated on December 22, 2019, with the updated search yielding 467 references (see Fig. 1).

In addition, we conducted a search on systematic reviews and meta-analyses on this theme and searched for relevant articles this way (in particular [14-16], see the latter for further detail on the search strategy). As the second step, all articles which included AUDs as exposure were selected as the basis of the analyses of this paper.

For measurement of AUDs, we included the following: hospital record, other record in the healthcare or government database (e.g., registration), physician judgement, standardized measurement with a validated instrument such as the World Health Organization (WHO) Composite International Diagnostic Interview [17], self-report about major criteria of AUDs (for a general discussion of criteria, see $[6,18])$. While chronic heavy drinking above $80 \mathrm{~g}$ pure alcohol per day before or at some point over the course of the disease could be part of the inclusion criteria (e.g., [19]), it alone did not suffice for inclusion in the study, as no generally accepted quantitative threshold for AUDs based on level of drinking has yet been established [7, 20]. We also excluded studies solely based on screening instruments, such as the CAGE [21] or the AUDIT [22].

All articles were screened by two of the authors (either LLF, MG, or JR). An overview of the selection process can be found in Fig. 1 [23]. All included studies were extracted by two authors (LLF and JR) for key information (study characteristics: title, authors, year published, country, study design, year of study; study population: total number of patients with HCV infection; participant details: mean age, sex, HIV coinfection, number of people with AUD; measurement of AUD; risk relations: relative risk indicator, confidence intervals, $p$ value, adjustments (other covariates); and outcomes).

\section{Statistical methods}

Relative Risk estimates (either Odds Ratios, Relative Risks or Hazard Ratios $[13,24])$ were taken directly from the respective article or calculated based on a $2 * 2$ table [25] or, in one case, using the methodology specified by Hamling et al. [26].

In the main analysis, only decompensated liver cirrhosis or its main constituents (defined above [9, 10]) as confirmed from medical records, hospitalization or death was chosen as the endpoint ( $n=7$ estimates from 5 studies). A random effect meta-analysis [27], accounting for the hierarchical structure of the data (three estimates from one study) was conducted [28].

In a secondary analysis, we repeated the random-effect meta-analyses for all estimates of progression of liver 


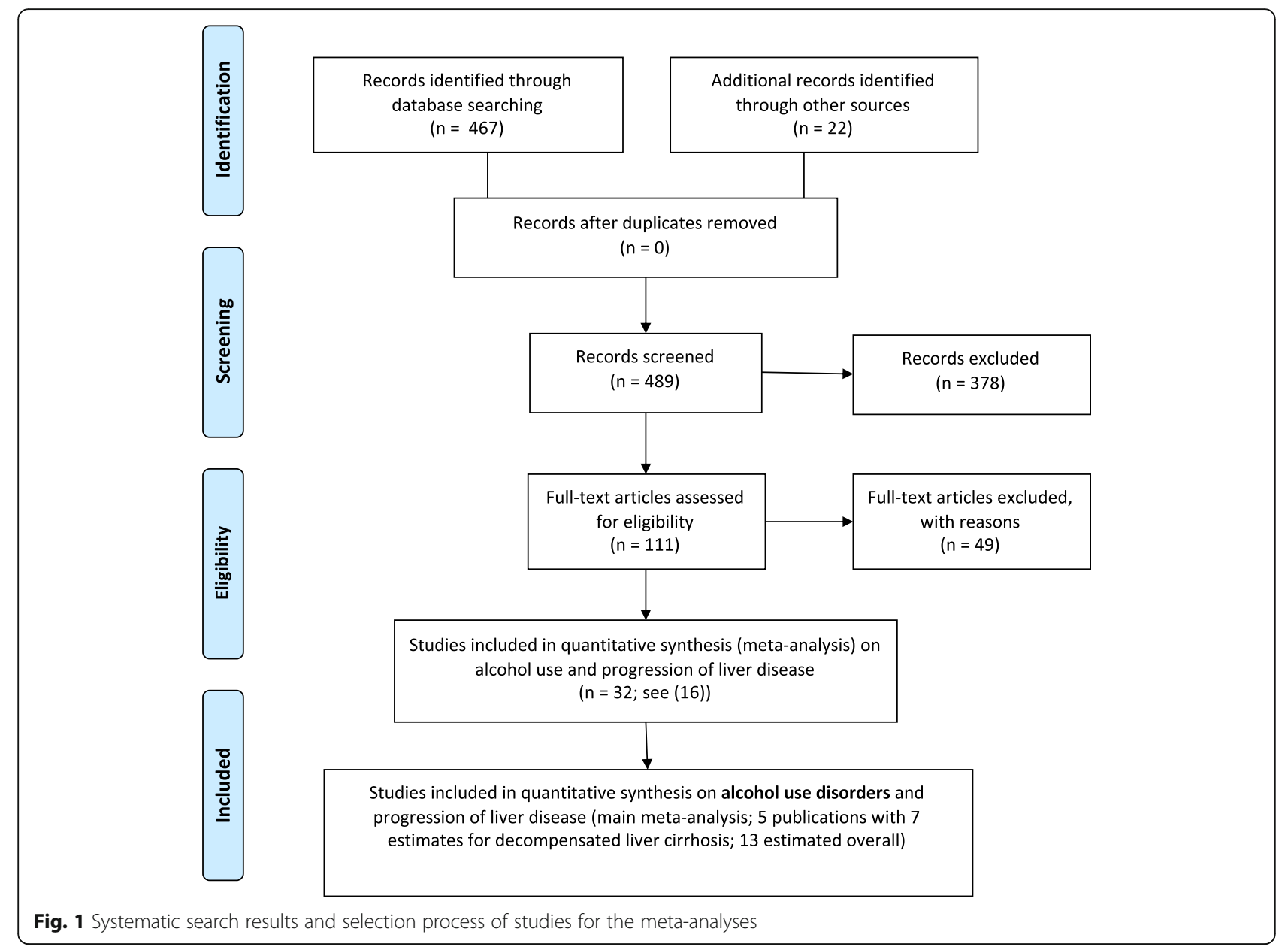

disease, i.e. applied a looser inclusion criterion. Here, the following endpoints were including as well (see also Table 1: advanced fibrosis, liver cirrhosis, liver deaths). For both models, we tested if adjustment for important covariates has an impact on the overall effect. Cochran's $\mathrm{Q}$ and the I-squared statistic were used as indicators for heterogeneity $[38,39]$.

Lastly, we calculated the population-attributable fraction (PAF), i.e. the proportion of cases with liver disease progression that could have been avoided if no person with a chronic HCV infection had an AUD. The PAF was calculated using Formula 1 by combining data on the prevalence of AUD (P) with corresponding RRs [40]. All analyses were performed with $\mathrm{R}$ version 3.6.1 [41].

$$
P A F=\frac{P(R R-1)}{1+P(R R-1)}
$$

\section{Results}

Table 1 gives an overview of the studies and their characteristics. In total, studies including 286,641 people with chronic $\mathrm{HCV}$ infection fulfilled the inclusion criteria, of whom 63,931 (22.3\%) qualified for an AUD.

In the main analysis, 268,114 people with chronic HCV were included, of whom 21,882 had decompensated liver cirrhosis (8.2\%). A total of 63,335 people, or $23.6 \%$ of this sample, were identified with AUD, a proportion much higher than seen in the general population $[2,42]$. Using decompensated liver cirrhosis as the outcome for the main analysis (based on $n=7$ estimates), an AUD diagnosis was associated with a 3.3-fold risk for progression of liver disease among people with a chronic HCV infection (95\% Confidence Interval (CI): 1.8-4.8), see Fig. 2). There was no significant difference between studies that were adjusted for important covariates and those that were not ( $p$-value $=0.878)$. In terms of population attributable fractions, slightly less than 4 out ten cases of decompensated liver cirrhosis cases were attributable to AUD: $35.2 \%$ (95\% CI: $16.2-47.1 \%$ ).

As a secondary analysis, all estimates of liver disease progression were pooled, which yielded a similar overall effect of AUD as compared to the main analysis $(n=13$ estimates; OR $=3.7$; 95\% CI: $2.2-5.3$; see Supplementary Materials Figure S1). The risk difference between 


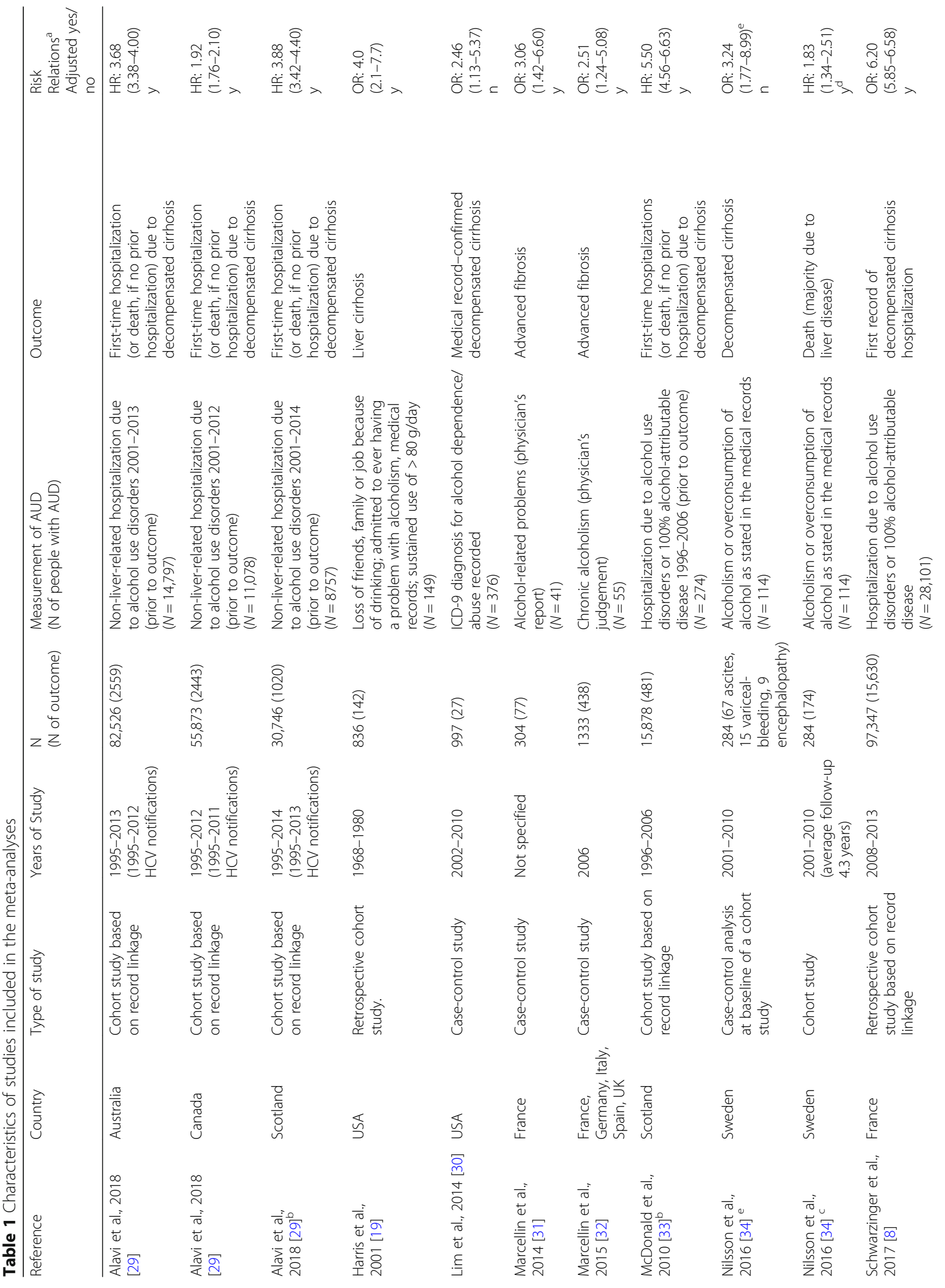




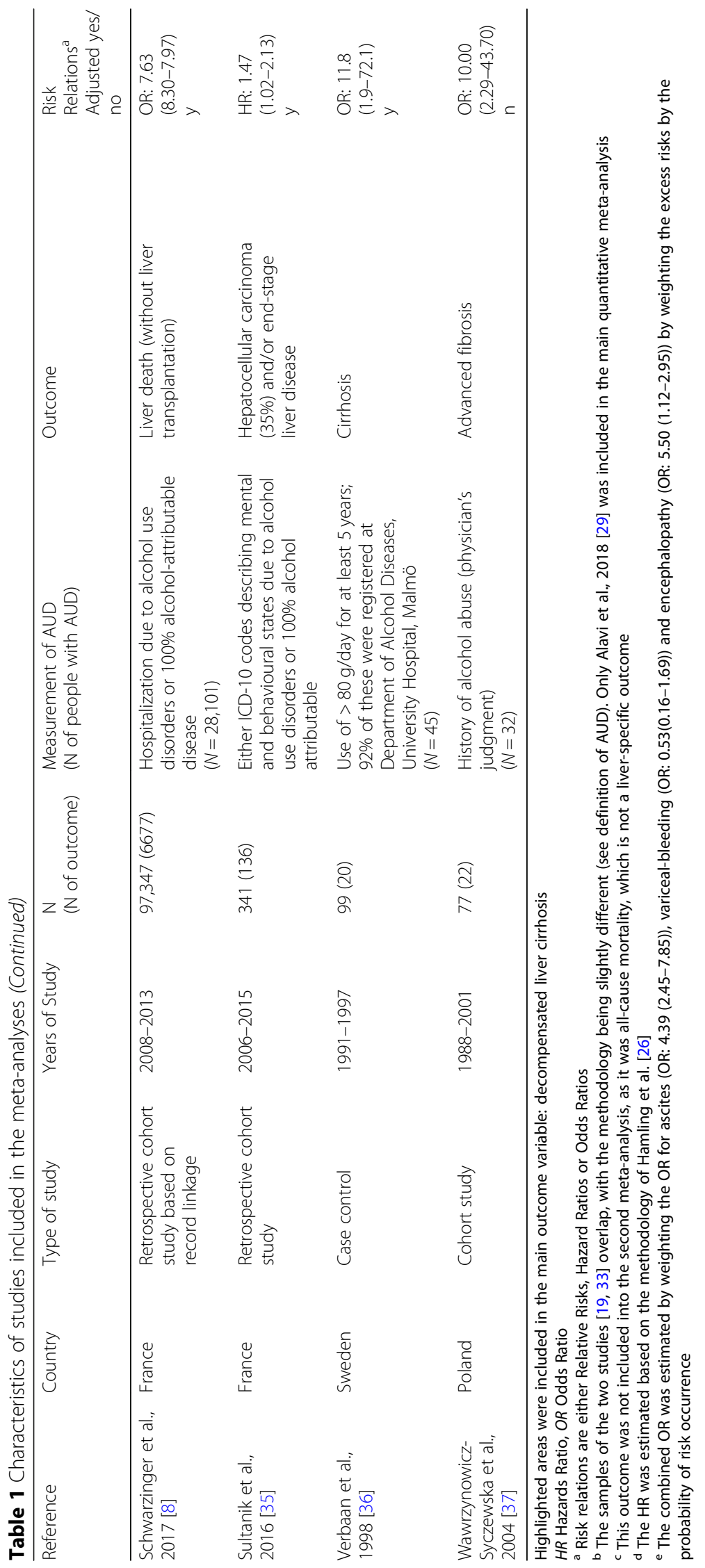




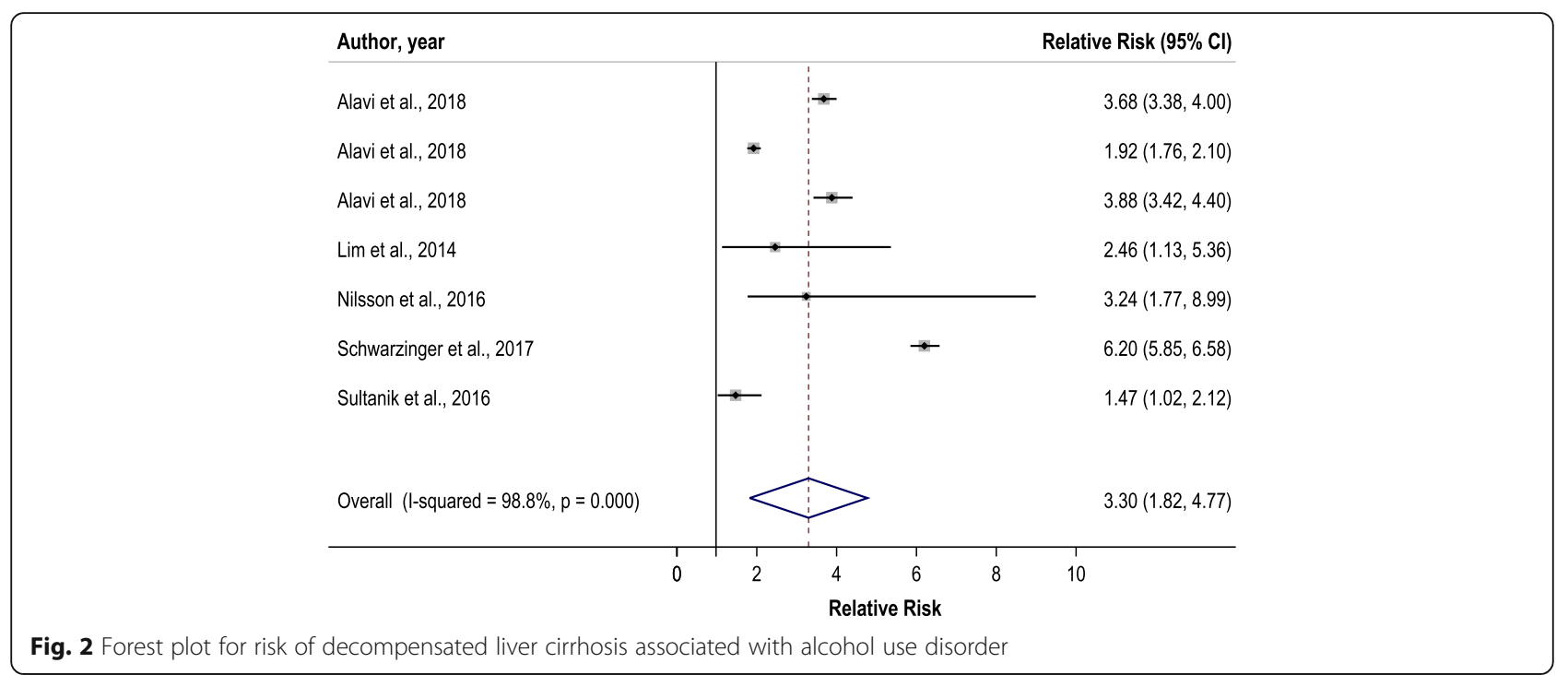

decompensated liver cirrhosis and the other indicators of liver disease progression was not significant (relative risk ratio: 0.6; 95\% CI: 0.3-1.3). Again, adjustment for important covariates was not related to substantial reductions of the effect ( $p$-value $=0.969)$. Again, this would be equivalent to about $40 \%$ of cases with liver progression being attributable to AUDs (attributable fraction: 39.3\%; 95\% CI: 21.9-50.4\%).

In both analyses, substantial heterogeneity was identified using Cochran's Q statistic ( [38]; main analysis for $n=7$ estimates: $\mathrm{Q}(\mathrm{df}=6)=507.3, p<.001$; secondary analysis for $n=13$ estimates: $\mathrm{Q}(\mathrm{df}=12)=1184.5$, $\mathrm{p}<.001$ ), presumably associated with the large variation in sample sizes in the included studies (minimum $=77$, maximum $=97,347$ ). The I-square statistics also indicated substantial heterogeneity.

\section{Discussion}

Before discussing the results and implications of our findings further, we would like to highlight the potential limitations.

\section{Limitations}

One limitation to this review and meta-analysis is the reliance on aggregate data, which relies on the qualities of the underlying published studies, based on heterogeneous populations, different study designs and different statistical models, and in different historical periods of time [11]. Even though the populations were heterogeneous, almost all of the studies included are from highincome countries. Given the global load of alcoholattributable liver cirrhosis burden [43, 44], we urgently need data from other regions of the world, especially from regions with a high prevalence of HCV infections such as Africa and Central Asia [2, 45], but also from countries in Eastern Europe where prevalence of HCV infections and of AUDs are high (e.g., Moldova, Georgia [46]).

Also, the largest studies [8, 29] relied on medical hospital records of AUD, which likely underestimated the true prevalence, as this disorder is highly stigmatized [47] and neither necessarily disclosed nor recorded in hospitals or healthcare settings (for a wider discussion, see $[48,49])$, even for $100 \%$ alcohol-attributable disorders $[50,51]$. However, the bias introduced by underestimating the prevalence of AUDs is conservative; the attributable fractions would likely be higher with higher prevalence (for formulas, see [40]). Additionally, relying on hospital records for the largest studies removes potential biases due to self-report of AUDs [52].

Another potential limitation involves the exclusion of studies where AUDs could only have been inferred by a mention of chronic heavy drinking or other drinking behaviours closely related to AUDs. On the one hand, heavy drinking is a key characteristic of AUDs [20]. To give one example, there is a high likelihood that lifetime drinkers with more than $175 \mathrm{~g}$ pure alcohol consumed daily-such as in the study of Corrao and colleagues [53] - would qualify for AUDs had this condition been measured with validated instruments. One the other hand, it is hard to draw a threshold. In the same study by Corrao and colleagues, the following thresholds were used to indicate the drinking level: $50 \mathrm{~g}, 75 \mathrm{~g}, 100 \mathrm{~g}, 125$ $\mathrm{g}$ and $150 \mathrm{~g}$ pure alcohol per day. It is not clear which of these drinking-level categories would indicate AUD. Thus, while AUDs constitute a common medical diagnosis, the use of this diagnosis-which is clinically relevant and can be used in health services research-in epidemiological research may lead to biases, as the active ingredient in disease progression-ethanol-is only 
indirectly assessed (see also [7, 54]). Another aspect of patterns of drinking deserve mentioning. These patterns - especially the prevalence of heavy episodic drinking differ vastly between the countries examined here [55]. It has been shown that a pattern of daily heavy drinking is most detrimental for worsening of liver disease [56, 57], for daily drinking is less prevalent among heavy drinkers in countries like Poland or Scotland, compared countries like France, to mention just three of the countries in our sample. Without measuring patterns of drinking at the individual level, variation is introduced into our results. Future research should not only rely on wide categories such as AUD [6], but should measure drinking level and patterns.

As we wanted to conduct a meta-analysis with a narrow outcome - decompensated liver cirrhosis, we defined our search terms excluding wider definitions such as hepatocellular carcinoma. Indeed, we achieved this goal, and only in one study [35], a minority of cases included hepatocellular carcinoma. This does not mean, however, that AUDs do not causally impact on hepatocellular carcinoma in people with chronic $\mathrm{HCV}$ infections. As Schwarzinger and colleagues demonstrated in the national French hospital cohort comprising 6404 patients with hepatocellular carcinoma [8], AUDs were associated with a fourfold-increased risk $(4.23$; 95\% CI: 3.99-4.49).

\section{Alcohol use disorders as a key determinant of liver disease progression}

Our results show that AUDs are quite common among people with chronic HCV infections, and that they are a key determinant for worsening of liver disease. Our design did not allow us to answer the question of whether alcohol use or AUDs were the only factor in disease progression (see [15]); however, other research seems to indicate that $\mathrm{HCV}$ in people with AUDs also showed increased disease progression (e.g., $[6,58,59])$ and, thus, there seems to be an interaction effect of alcohol use and HCV infection. There are also plausible biological pathways, such as increased viral replication and altered immune response [60].

Our design also does not answer the question regarding a dose-response relationship for alcohol use, i.e., whether all levels of alcohol use are detrimental for liver disease progression (see $[16,61]$ ). However, we can clearly state that AUDs, with their high levels of alcohol consumption, produce a markedly worsened progression for liver diseases, and were responsible for about $40 \%$ of all these complications in the large cohorts underlying our study (see [62, 63], for further discussion). Such a high attributable fraction also calls into question the compartmentalization of liver cirrhosis into subtypes/ categories $[4,5]$.

\section{Conclusions}

AUDs are relatively frequent in people with chronic $\mathrm{HCV}$ infections and contributed markedly to progression of liver disease. Two main conclusions result: despite the current clinical compartmentalization, alcohol use and AUDs should be assessed in patients with liver cirrhosis of any etiology (see also [64] for the dose-response relationship for alcohol use on any kind of liver cirrhosis), and irrespective, if the $\mathrm{HCV}$ infection has been treated successfully of not. This is even true for so-called "nonalcoholic" liver disease categories, where AUDs do not play a role by definition, but alcohol use still may [65]. But assessment is not sufficient, AUDs need to be treated by either achieving full abstinence (the best outcome of alcohol interventions for any kind of liver disease [66]) or, if this is not possible, reducing consumption to the highest degree possible [67-69].

\section{Supplementary information}

Supplementary information accompanies this paper at https://doi.org/10. 1186/s13011-020-00287-1.

Additional file 1. Supplementary materials.

Additional file 2: Figure S1. Forest plot for risk of negative course of liver disease associated with alcohol use disorder.

\section{Abbreviations}

AUD/AUDs: Alcohol Use Disorder(s); Cl: Confidence Interval; HCV: Hepatitis C Virus; PAF: Population-attributable fraction; PRISMA: Preferred Reporting Items for Systematic Reviews and Meta-Analyses; RE model: Random-effects model; WHO: World Health Organization

\section{Acknowledgements \\ The authors would like to thank Ms. Astrid Otto for copy-editing and referen- cing assistance.}

\section{Authors' contributions}

JR conceptualized the study and JR and LLF wrote a first draft. MG did the systematic searches. LLF, MG and JR chose the studies to be included, and LLF and JR extracted information. JM and KS did the main statistical analysis. All authors reviewed various versions of the text and approved the final version.

\section{Funding}

This contribution was supported by the WHO Collaborating Centre for Addiction and Mental Health at the Centre for Addiction and Mental Health, Toronto, Canada. JR acknowledges funding from the Canadian Institutes of Health Research, Institute of Neurosciences, and Mental Health and

Addiction (CRISM Ontario Node grant no. SMN-13950). Research reported in this publication was also supported by the National Institute on Alcohol Abuse and Alcoholism of the National Institutes of Health (NIAAA) [Award Number R01AA024443]. This research was conducted as part of the Calibrated Agent Simulations for Combined Analysis of Drinking Etiologies (CASCADE) project and we would like to thank the whole CASCADE team for their input to wider discussions in generating the research reported in this paper. Content is the responsibility of the authors and does not reflect official positions of NIAAA or the National Institutes of health. In addition, JR was supported for the general systematic search on alcohol use, HCV infection and progression of liver disease by a consultant contract of the Pan American Health Organization (NMH/NV/IPC/18/05).

Availability of data and materials

All data has been derived from published studies. 


\section{Ethics approval and consent to participate}

Not applicable, as the analyses were all based on published anonymized data.

\section{Consent for publication}

Not applicable in a secondary data analysis.

\section{Competing interests}

None declared.

\section{Author details}

'Preventive Medicine and Public Health, Preventive Medicine, Universitary Hospital "12 de Octubre", Avda de Córdoba s/n 28041, Madrid, Spain. ${ }^{2}$ Institute for Mental Health Policy Research, Centre for Addiction and Mental Health, 33 Russell Street, Room T420, Toronto, Ontario M5S 2S1, Canada. ${ }^{3}$ Dalla Lana School of Public Health, University of Toronto, 155 College Street, Toronto, Ontario M5T 1P8, Canada. ${ }^{4}$ Center for Interdisciplinary Addiction Research (ZIS), Department of Psychiatry and Psychotherapy, University Medical Center Hamburg-Eppendorf (UKE), Martinistraße 52, 20246 Hamburg, Germany. ${ }^{5}$ Institute of Clinical Psychology and Psychotherapy \& Center of Clinical Epidemiology and Longitudinal Studies (CELOS), Technische Universität Dresden, Chemnitzer Str. 46, 01187 Dresden, Germany. ${ }^{6}$ Campbell Family Mental Health Research Institute, Centre for Addiction and Mental Health, 33 Russell Street, Toronto, Ontario M5T 2S1, Canada. ${ }^{7}$ Faculty of Medicine, Institute of Medical Science, University of Toronto, Medical Sciences Building, 1 King's College Circle, Room 2374, Toronto, Ontario M5S 1A8, Canada. ${ }^{8}$ Department of Psychiatry, University of Toronto, 250 College Street, 8th floor, Toronto, Ontario M5T 1R8, Canada. ${ }^{9}$ Department of International Health Projects, Institute for Leadership and Health Management, I.M. Sechenov First Moscow State Medical University, Trubetskaya str., 8, b. 2, Moscow, Russian Federation 119992.

\section{Received: 21 February 2020 Accepted: 23 June 2020}

\section{Published online: 30 June 2020}

\section{References}

1. World Health Organization. Global Health Estimates (GHE).2019 Accessed: 10/02/2020; Available from: http://www.who.int/healthinfo/global_burden_ disease/en/..

2. Global Health Data Exchange (GHDx). GBD Results Tool. . Seattle, Washington: Institute for Health Metrics and Evaluation; 2019. Available from: http://ghdx.healthdata.org/gbd-results-tool. Accessed: 10/02/2020.

3. World Health Organization. ICD-11 for Mortality and Morbidity Statistics (ICD-11 MMS): 2018 version.2018 Accessed: 08/02/2020; Available from: https://icd.who.int/browse11/l-m/en.

4. Eslam M, Sanyal AJ, George J. Toward more accurate nomenclature for fatty liver diseases. Gastroenterology. 2019;157(3):590-3.

5. Lange $S$, Roerecke $M$, Rehm J. For most fully alcohol-attributable diagnoses in the ICD, the etiological specification should be removed. Adicciones. 2020;32(2):90-3.

6. Carvalho AF, Heilig M, Perez A, Probst C, Rehm J. Alcohol use disorders. Lancet. 2019;394(10200):781-92

7. Rehm J, Marmet S, Anderson P, Gual A, Kraus L, Nutt DJ, et al. Defining substance use disorders: do we really need more than heavy use? Alcohol Alcohol. 2013;48(6):633-40.

8. Schwarzinger M, Baillot S, Yazdanpanah Y, Rehm J, Mallet V. Contribution of alcohol use disorders on the burden of chronic hepatitis C in France, 20082013: a nationwide retrospective cohort study. J Hepatol. 2017;67(3):454-61.

9. European Association for the Study of the Liver. EASL clinical practice guidelines for the management of patients with decompensated cirrhosis. J Hepatol. 2018;69(2):406-60.

10. Mansour D, McPherson S. Management of decompensated cirrhosis. Clin Med (London, England). 2018;18(Suppl 2):s60-s5.

11. Blettner M, Sauerbrei W, Schlehofer B, Scheuchenpflug T, Friedenreich C. Traditional reviews, meta-analyses and pooled analyses in epidemiology. Int J Epidemiol. 1999;28(1):1-9.

12. PRISMA. The PRISMA Statement. PRISMA; 2015. Available from: http://www. prisma-statement.org/PRISMAStatement/PRISMAStatement. Accessed: 23/12/ 2019.

13. Rothman KJ, Greenland S, Lash TL. Modern Epidemiology. Third ed. Philadelphia: Lippincott Williams \& Wilkins; 2008.
14. Hutchinson SJ, Bird SM, Goldberg DJ. Influence of alcohol on the progression of hepatitis C virus infection: a meta-analysis. Clin Gastroenterol Hepatol. 2005;3(11):1150-9.

15. Vento S, Cainelli F. Does hepatitis C virus cause severe liver disease only in people who drink alcohol? Lancet Infect Dis. 2002;2(5):303-9.

16. Llamosas-Falcón L, Shield KD, Gelovany M, Manthey J, Rehm J. Alcoholattributable hepatitis C burden. Toronto: Centre for Addiction and Mental Health; 2020.

17. Harvard College. The World Health Organization World Mental Health Composite International Diagnostic Interview (WHO WMH-CIDI). 2020. Available from: https://www.hcp.med.harvard.edu/wmhcidi/about-the-whowmh-cidi/. Accessed: 10/02/2020.

18. Rehm J, Heilig M, Gual A. ICD-11 for alcohol use disorders: not a convincing answer to the challenges. Alcohol Clin Exp Res. 2019;43(11):2296-300.

19. Harris DR, Gonin R, Alter HJ, Wright EC, Buskell ZJ, Hollinger FB, et al. The relationship of acute transfusion-associated hepatitis to the development of cirrhosis in the presence of alcohol abuse. AnnInternMed. 2001;134(2):120-4

20. Rehm J, Anderson P, Gual A, Kraus L, Marmet S, Nutt DJ, et al. The tangible common denominator of substance use disorders: a reply to commentaries to Rehm et al. (2013a). Alcohol Alcoholism (Oxford, Oxfordshire). 2014;49(1): 118-22.

21. Dhalla S, Kopec JA. The CAGE questionnaire for alcohol misuse: a review of reliability and validity studies. Clin Invest Med. 2007:30(1):33-41.

22. Lange S, Shield K, Monteiro M, Rehm J. Facilitating screening and brief interventions in primary care: a systematic review and meta-analysis of the AUDIT as an Indicator of alcohol use disorders. Alcohol Clin Exp Res. 2019; 43(10):2028-37.

23. PRISMA. Prism Flow Diagram. 2015. Available from: http://prisma-statement. org/prismastatement/flowdiagram.aspx. Accessed: 10/02/2020.

24. Greenland S. Interpretation and choice of effect measures in epidemiologic analyses. Am J Epidemiol. 1987;125(5):761-8.

25. Fleiss J, Levin B, Cho PM. Statistical Methods for Rates and Proportions. Third Edition ed. Hoboken: John Wiley \& Sons; 2003. p. 2003.

26. Hamling J, Lee $P$, Weitkunat $R$, Ambuhl M. Facilitating meta-analyses by deriving relative effect and precision estimates for alternative comparisons from a set of estimates presented by exposure level or disease category. Stat Med. 2008;27(7):954-70.

27. DerSimonian R, Laird N. Meta-analysis in clinical trials. Control Clin Trials. 1986;7(3):177-88.

28. Schwarzer G, Carpenter JR, Rücker G. Meta-analysis with R. New York: Springer-Verlag; 2015.

29. Alavi M, Janjua NZ, Chong M, Grebely J, Aspinall EJ, Innes H, et al. The contribution of alcohol use disorder to decompensated cirrhosis among people with hepatitis C: an international study. J Hepatol. 2018;68(3):393401.

30. Lim JK, Tate JP, Fultz SL, Goulet JL, Conigliaro J, Bryant KJ, et al. Relationship between alcohol use categories and noninvasive markers of advanced hepatic fibrosis in HIV-infected, chronic hepatitis C virus-infected, and uninfected patients. Clin Infect Dis. 2014;58(10):1449-58.

31. Marcellin F, Roux P, Loko MA, Lions C, Caumont-Prim A, Dabis F, et al. High levels of alcohol consumption increase the risk of advanced hepatic fibrosis in HIV/hepatitis C virus-coinfected patients: a sex-based analysis using transient elastography at enrollment in the HEPAVIH ANRS CO13 cohort. Clin Infect Dis. 2014;59(8):1190-2.

32. Marcellin P, Grotzinger K, Theodore D, Demuth D, Manns M, Banares Canizares $R$, et al. Severity of liver disease among chronic hepatitis $C$ patients: an observational study of 4594 patients in five European countries. J Gastroenterol Hepatol. 2015;30(2):364-71.

33. McDonald SA, Hutchinson SJ, Bird SM, Mills PR, Robertson C, Dillon JF, et al. Hospitalization of hepatitis C-diagnosed individuals in Scotland for decompensated cirrhosis: a population-based record-linkage study. Eur J Gastroenterol Hepatol. 2010;22(1):49-57.

34. Nilsson E, Anderson H, Sargenti K, Lindgren S, Prytz H. Incidence, clinical presentation and mortality of liver cirrhosis in southern Sweden: a 10-year population-based study. Aliment Pharmacol Ther. 2016;43(12):1330-9.

35. Sultanik P, Kramer L, Soudan D, Bouam S, Meritet JF, Vallet-Pichard A, et al. The relationship between liver stiffness measurement and outcome in patients with chronic hepatitis $C$ and cirrhosis: a retrospective longitudinal hospital study. Aliment Pharmacol Ther. 2016;44(5):505-13. 
36. Verbaan H, Widell A, Bondeson L, Andersson K, Eriksson S. Factors associated with cirrhosis development in chronic hepatitis $\mathrm{C}$ patients from an area of low prevalence. J Viral Hepat. 1998;5(1):43-51.

37. Wawrzynowicz-Syczewska M, Kubicka J, Lewandowski Z, Boron-Kaczmarska A, Radkowski M. Natural history of acute symptomatic hepatitis type C. Infection. 2004;32(3):138-43.

38. Cochran WG. The combination of estimates from different experiments. Biometrics. 1954;10(1):101-29.

39. Higgins JP, Thompson SG. Quantifying heterogeneity in a meta-analysis. Stat Med. 2002;21(11):1539-58.

40. Levin ML. The occurrence of lung cancer in man. Acta Unio Int Contra Cancrum. 1953;9(3):531-41.

41. R Core Team. A language and environment for statistical computing. $R$ Foundation for Statistical Computing. Vienna, Austria: R Foundation for Statistical Computing,; 2019. Available from: www.R-project.org/. Accessed: 10/02/2020

42. World Health Organization. Global status report on alcohol and health 2018 2018 Accessed: 05/20/2019; Available from: https://www.who.int/substance_ abuse/publications/global_alcohol_report/en/.

43. Rehm J, Shield KD. Global burden of alcohol use disorders and alcohol liver disease. Biomedicines. 2019;7(4):99.

44. Shield K, Manthey J, Rylett M, Probst C, Wettlaufer A, Parry CDH, et al. National, regional, and global burdens of disease from 2000 to 2016 attributable to alcohol use: a comparative risk assessment study. Lancet Public Health. 2020;5(1):E51-61.

45. Thrift AP, El-Serag HB, Kanwal F. Global epidemiology and burden of HCV infection and HCV-related disease. Nat Rev Gastroenterol Hepatol. 2017; 14(2):122-32.

46. Maistat L, Kravchenko N, Reddy A. Hepatitis C in Eastern Europe and Central Asia: a survey of epidemiology, treatment access and civil society activity in eleven countries. Hepatol Med Policy. 2017;2(1):9.

47. Schomerus $G$, Lucht $M$, Holzinger A, Matschinger $H$, Carta MG, Angermeyer MC. The stigma of alcohol dependence compared with other mental disorders: a review of population studies. Alcohol Alcoholism (Oxford, Oxfordshire). 2011;46(2):105-12.

48. Hanschmidt F, Manthey J, Kraus L, Scafato E, Gual A, Grimm C, et al. Barriers to Alcohol Screening Among Hypertensive Patients and the Role of Stigma: Lessons for the Implementation of Screening and Brief Interventions in European Primary Care Settings. Alcohol Alcoholism (Oxford, Oxfordshire). 2017;52(5):572-9.

49. Chen $\mathrm{CH}$, Chen WJ, Cheng AT. Prevalence and identification of alcohol use disorders among nonpsychiatric inpatients in one general hospital. Gen Hosp Psychiatry. 2004;26(3):219-25

50. Rehm J, Hasan OSM, Imtiaz S, Neufeld M. Quantifying the contribution of alcohol to cardiomyopathy: A systematic review. Alcohol (Fayetteville, NY). 2017;61:9-15.

51. Puffer RR, Griffith GW. Patterns of urban mortality: report of the interAmerican investigation of mortality. Washington, D.C: Pan American Health Organization; 1967.

52. Del Boca FK, Darkes J. The validity of self-reports of alcohol consumption: state of the science and challenges for research. Addiction (Abingdon, England). 2003;98 Suppl 2:1-12.

53. Corrao G, Arico S. Independent and combined action of hepatitis C virus infection and alcohol consumption on the risk of symptomatic liver cirrhosis. Hepatology (Baltimore, Md). 1998;27(4):914-9.

54. Rehm J. How should prevalence of alcohol use disorders be assessed globally? Int J Methods Psychiatr Res. 2016;25(2):79-85.

55. Manthey J, Shield KD, Rylett M, Hasan OSM, Probst C, Rehm J. Global alcohol exposure between 1990 and 2017 and forecasts until 2030: a modelling study. Lancet. 2019;393(10190):2493-502.

56. Askgaard G, Gronbaek M, Kjaer MS, Tjonneland A, Tolstrup JS. Alcohol drinking pattern and risk of alcoholic liver cirrhosis: a prospective cohort study. J Hepatol. 2015;62(5):1061-7.

57. Rehm J, Roerecke M. Patterns of drinking and liver cirrhosis - what do we know and where do we go? J Hepatol. 2015;62(5):1061-7.

58. Sanvisens A, Munoz A, Bolao F, Zuluaga P, Farre M, Jarrin I, et al. Do serum markers of liver fibrosis vary by HCV infection in patients with alcohol use disorder? Drug Alcohol Depend. 2018;188:180-6.

59. Muga R, Sanvisens A, Jarrin I, Fuster D, Bolao F, Tor J, et al. Hepatitis C infection substantially reduces survival of alcohol-dependent patients. Clin Epidemiol. 2018;10:897-905.
60. Novo-Veleiro I, Alvela-Suárez L, Chamorro A-J, González-Sarmiento R, Laso FJ. Marcos M. Alcoholic liver disease and hepatitis C virus infection. World J Gastroenterol. 2016;22(4):1411-20.

61. Peters MG, Terrault NA. Alcohol use and hepatitis C. Hepatology (Baltimore, Md). 2002;36(5 Suppl 1):S220-S5.

62. Alavi M, Law MG, Dore GJ. Reply to: "'Who killed JR': chronic hepatitis C or alcohol use disorders?". J Hepatol. 2018;68(5):1099-100.

63. Schwarzinger M, Rehm J, Mallet V. "who killed JR": chronic hepatitis C or alcohol use disorders? J Hepatol. 2018;68(5):1098-9.

64. Roerecke M, Vafaei A, Hasan OSM, Chrystoja BR, Cruz M, Lee R, et al. Alcohol consumption and risk of liver cirrhosis: a systematic review and metaanalysis. Am J Gastroenterol. 2019;114(10):1574-86.

65. Roerecke M, Nanau R, Rehm J, Neuman M. Ethnicity matters: a systematic review and meta-analysis of the non-linear relationship between alcohol consumption and prevalence and incidence of hepatic Steatosis. EBioMedicine. 2016:8:317-30.

66. Altamirano J, Michelena J. Alcohol consumption as a cofactor for other liver diseases. Clini Liver Dis. 2013;2(2):72-5.

67. Rehm J, Roerecke M. Reduction of drinking in problem drinkers and allcause mortality. Alcohol Alcoholism (Oxford, Oxfordshire). 2013;48(4):509-13.

68. Lieber CS, Weiss DG, Groszmann R, Paronetto F, Schenker S II. Veterans affairs cooperative study of polyenylphosphatidylcholine in alcoholic liver disease. Alcohol Clin Exp Res. 2003;27(11):1765-72

69. Charlet K, Heinz A. Harm reduction-a systematic review on effects of alcohol reduction on physical and mental symptoms. Addict Biol. 2017; 22(5):1119-59.

\section{Publisher's Note}

Springer Nature remains neutral with regard to jurisdictional claims in published maps and institutional affiliations.

Ready to submit your research? Choose BMC and benefit from:

- fast, convenient online submission

- thorough peer review by experienced researchers in your field

- rapid publication on acceptance

- support for research data, including large and complex data types

- gold Open Access which fosters wider collaboration and increased citations

- maximum visibility for your research: over $100 \mathrm{M}$ website views per year

At BMC, research is always in progress.

Learn more biomedcentral.com/submissions 